\title{
OS MALES DA CONTEMPORANEIDADE ENGENDRADO AO SUJEITO WORKAHOLIC
}

\section{ARTIGO ORIGINAL}

MASCHIO, Priscila Fernanda ${ }^{1}$

FRANCISCON, Thaís Emanuelly ${ }^{2}$

SCATOLIN, Henrique Guilherme ${ }^{3}$

MASCHIO, Priscila Fernanda. FRANCISCON, Thaís Emanuelly. SCATOLIN, Henrique Guilherme. Os males da contemporaneidade engendrado ao sujeito Workaholic. Revista Científica Multidisciplinar Núcleo do Conhecimento. Ano 05, Ed. 11, Vol. 18, pp. 181-202. Novembro de 2020. ISSN: 2448-0959, Link de acesso: https://www.nucleodoconhecimento.com.br/psicologia/sujeito-workaholic

\section{RESUMO}

Atualmente o trabalho constituí concepções sobre o homem, sendo esse conhecido como parte do processo dentro do mundo do trabalho. Dada a significância dos males da contemporaneidade no sujeito workaholic, o presente artigo discorre sobre as implicações laborais e sociais na constituição desse sujeito. A partir desse cenário, o artigo tem como indagação a seguinte problemática: na atualidade, considerando as descompensações das rotinas laborais, como o sujeito workaholic pode ser visualizado e cuidado pelos profissionais da Psicologia? Para o desenvolvimento

1 Pós-Graduação em Psicologia Organizacional e do Trabalho. Graduação em Psicologia.

2 Pós-Graduação em Psicologia Organizacional e do Trabalho. Graduação em Psicologia.

${ }^{3}$ Orientador. Doutorado em Psicologia (Psicologia Clínica). Mestrado em Psicologia (Psicologia Clínica). Graduação em Psicologia. 
desta pesquisa, na fundamentação teórica foi necessário contextualizar as mudanças no mercado de trabalho que propiciam o surgimento do adoecimento referente ao workaholic, com a intenção de identificar a influência das relações sociais sobre o adoecimento do trabalhador e compreender quem é o sujeito workaholic no mundo do trabalho formal. Esta pesquisa aponta como resultado a existência de diferentes abordagens que podem auxiliar na busca por medidas e intervenções ao adoecimento no processo do trabalho, concluindo que há necessidade do profissional da Psicologia no contexto das organizações por esse ser apto a mobilizar atuações preventivas no que tange os processos de saúde/doença mental na atuação profissional.

Palavras-chave: Saúde do Trabalhador, workaholic, trabalho.

\section{INTRODUÇÃO}

Este artigo tem como objeto de estudo os males sociais e laborais engendrados ao sujeito workaholic a partir do mundo atual. Existem várias definições do workaholic, pois é um tema que vem sendo muito discutido. Uma das definições é o sujeito obcecado pelo trabalho, deixando de lado todas as relações pessoais para então se debruçar no trabalho em tempo árduo de longa durabilidade (GOMES; SOARES, 2011).

O Workaholic é uma pessoa compreendida como "viciada" em trabalho, sendo que o referido pode vivenciar disfunções físicas, mentais e emocionais, causando assim o afastamento de pessoas próximas, entre elas familiares, amigos, colegas, tornandose solitário e isolado, desenvolvendo apenas atividades relacionadas ao trabalho e vivendo em função de tal (SOARES, 2018). Nessa conjuntura, o sujeito Workaholic executa sua função sem reclamar ou questionar, não compreendendo que a quantidade da demanda pode ser realizada como algo pejorativo que afetara sua saúde.

O tema workaholic deve ser discutido e estudado, pois atualmente as empresas estão cada vez mais ardilosas em relação ao sujeito e seus anseios; uma vez que a empresa está atenta aos sonhos, aspirações, desejos características que cada ser humano 
almeja dentro e fora de uma organização, para então tomar dessas complexidades uma forma de dedicação total e exclusiva voltada para dentro da empresa como resultado de sucesso e carreira (SERVA; FERREIRA, 2006).

Dessa forma, com o aumento de carga de trabalho e o envolvimento dos trabalhadores com as tarefas laborais, a empresa consegue com que esses funcionários que não estão preparados emocionalmente para lidar com os acúmulos, incidindo que eles ajam em função do trabalho, do sucesso, da carreira promissora, deixando de lado as interações e relações sociais que os cerca (GOMES, 2016). Isso pode ser explicitado como a importância do trabalho o delimita e o determina, condicionando seus afazeres e elencando prioridades, sobressaindo, portanto, as atividades vinculadas ao mundo do trabalho.

A partir da conjuntura citada acima, o objetivo deste estudo é contextualizar as mudanças no mercado de trabalho que propiciam o surgimento do adoecimento referente ao Workaholic na intencionalidade de identificar a influência das relações sociais sobre o adoecimento do trabalhador e compreender quem é o sujeito workaholic no mundo do trabalho formal.

A problemática abordada neste trabalho busca compreender como na atualidade, vivenciando as descompensações das rotinas laborais, quais são os fatores que levam o sujeito ao adoecimento psicológico, físico e quebra das relações sociais e como o sujeito workaholic pode ser visualizado e cuidado pelos profissionais da Psicologia.

Inicialmente questão referente ao adoecimento no mundo do trabalho chamou à atenção das autoras vista a importância de produções científicas em detrimento de como o profissional da saúde mental pode auxiliar na qualidade de vida e bem estar do sujeito trabalhador. Dessa forma foi exposto ao professor orientador o assunto que explanou sobre a "escola comportamental do estresse" e a "psicodinâmica do trabalho" como pontos importantes e base para iniciar uma discussão. 
A justificativa pelo estudo deste trabalho ocorre devido a dinâmica do trabalho atual que propicia o adoecimento, mas o adoecimento acaba sendo visualizado como individual e coletivo. Dessa forma, de acordo com o panorama explicitado, torna-se necessários estudos relacionados sobre o tema aqui abordado para propiciar a visibilidade desse sujeito já adoecido. Assim este trabalho irá demonstrar e requer um saber fazer, agir, reagir, sentir, pensar em diversos fatores referentes ao ponto de vista dos seres humanos. Rompendo assim com os paradigmas sociais e trazendo a tona a questão que o trabalho pode causar sofrimento criativo e não patogênico. Diante dessa questão implícita onde o sofrimento pode acontecer no ambiente de trabalho busca-se a possibilidade de novas formas de interações entre o homem, mundo do trabalho e o contexto social a qual está inserido (DEJOURS, 2004).

Coelho e Almeida Filho (2003) faz referência aos estudos epistemológicos de Canguilhem (1990) a respeito do que é saúde, sendo possibilitado realizar a relação entre a teoria e a prática. Para estas autoras, saúde é poder abusar da própria saúde, é criar novas regras, instituir novas normas para a vida, a vida contrariada. O ser saudável, então, diz respeito àquele que sabe fugir as normas e instituir. Neste meandro a doença consistiria em não conseguir assumir novas regras, a impossibilidade de criar outras para a vida. Assim, o autor aponta que o trabalho pode ser vivido como propiciador de diferentes vivências e experiências e o despertar do sofrimento criativo torna-se a possibilidade de vivenciar o trabalho sem adoecer.

Voltando ao nosso sujeito adoecido específico deste trabalho, o Workaholic, a análise realizada sobre o mesmo demonstra que ele se torna camuflado mediante ao contexto da atualidade, explicando que o contexto social e a busca de organizações do trabalho por sujeitos que ultrapassam limites param se sobressair dentro das instituições e essa compreensão é realizada também pela autora Mendes (2007) quando menciona que "a organização do trabalho promete utilizar o trabalho como forma de auto realização, levando o trabalhador muitas vezes a exaustão em nome dessa promessa" (MENDES, 2007, p. 45).

Nesse contexto, esse sujeito torna-se criações propícias ao mundo do trabalho, pois ao ultrapassar os próprios limites, buscando atingir suas necessidades de prazer, ele 
gera lucro sem questionar, acreditando estar na busca de seu desenvolvimento pessoal sem a percepção do quanto certas condições poderão emergir sofrimentos adoecedores e essas formas de ser dentro das instituições estão diretamente a formas de organização financeira e produtiva da atualidade (SOUZA; BERNANDO, 2019).

A relação entre os ambientes mencionados (contexto social e mundo do trabalho) são pontos a serem estudados para o profissional da Psicologia como fatores possibilitadores do adoecimento e que, se analisados, podem corroborar para com os cuidados relacionados à saúde psíquica e busca por equilíbrio do sujeito adoecido decorrente das pressões e descompensações da rotina laboral. Não somente os profissionais da Psicologia, ambos estão na busca para ajudarem e auxiliarem da melhor forma o sujeito trabalhador adoecido, cada qual na sua linha de pesquisa e abordagem. (SOUZA; BERNARDO, 2019).

Assim, este trabalho busca explanar o profissional da Psicologia como auxiliador no processo de ruptura da naturalização do sujeito workaholic que vivencia o sofrimento a partir da quebra do paradigma de um contexto social que produz sujeitos adoecidos. A estrutura de pensamento corrobora para o profissional de Psicologia como um técnico a ponto de auxiliar e criar intervenções a saúde ao trabalhador adoecido. Expondo, portanto, que a intervenção do psicólogo se dará na relação com outros sujeitos e grupos da instituição, e assim, pesquisadores de fenômenos institucionais devem atentar-se às relações que são estabelecidas dentro das instituições e as capacidades dessas emergirem seus problemas, pois as que assim fazem, serão colocadas a prova da tentativa de menor adoecimento (GUIRADO, 2004).

$\mathrm{Na}$ atualidade, vivenciando a problemática das descompensações das rotinas laborais, como o sujeito workaholic pode ser visualizado e cuidado pelos profissionais da Psicologia antes do adoecer? Dessa forma, o artigo pretende discorrer o quanto o contexto social e as organizações do mundo do trabalho prejudicam o sujeito, levando ao adoecimento e a possibilidade do profissional de Psicologia auxiliar no processo de não adoecimento de trabalhadores, trabalhando em sua prevenção primária. 


\section{METODOLOGIA}

A metodologia concerne em uma construção minuciosa referente às informações e dados que irão compor o trabalho, sendo essa construção necessária para fundamentar como dar-se-á o desenvolver de todo o processo e objetivo que o pesquisador se propõe a executar. O pesquisador necessita compreender a importância da sua implicação direta na produção textual, sendo ele o sujeito que começa a pensar e direcionar os caminhos a serem percorridos, pois para realizar uma pesquisa é necessário que o autor se atente a todo o processo de construção, desde o título até a conclusão. Assim está pesquisa deve ser realizada de modo criterioso, compondo as ações realizadas pelo pesquisador (GERHARDT; SILVEIRA, 2009).

Neste meandro, a metodologia aqui presente foi fundamentada em caráter de uma pesquisa de Revisão Bibliográfica, sendo ela compreendida como "um apanhado geral sobre os principais trabalhos já realizados, revestidos de importância, por serem capazes de fornecer dados atuais e relevantes relacionados com o tema". (LAKATOS; MARCONI, 2003, p.158). Esta forma de pesquisa não deve ser apenas uma repetição de conteúdos que já foram explanados, mas deve ter como propósito discutir o tema proposto de forma que chegue a conclusões que sejam inovadoras.

Para esta pesquisa foram utilizados os descritores: disciplina no Trabalho, satisfação no trabalho, doenças profissionais, medicina do trabalho, ambiente de trabalho e excluídos os descritores: mortalidade ocupacional, trabalho infantil, voluntários. Ressaltamos também a utilização de artigos voltados ao tema escritos entre 2000 até 2020, devido a evolução do conceito. A partir dos descritores selecionados, não serão aceitos artigos de experiência empírica e artigos de revisão sistemática para este estudo.

\section{FUNDAMENTAÇÃO TEÓRICA}

Vivemos em uma sociedade onde trabalhar faz parte integral de cultura e a existência humana. Na incessante busca por aprimorar seus conhecimentos, com o objetivo de 
vira-se o melhor naquilo que está desempenhando, o sujeito workaholic vive as relações antagônicas entre o amor e o ódio, prazer e desprazer. A busca para chegar em seus objetivos torna-se maior do que os auto cuidados, caracterizando essas situações adoecedoras por ser algo cíclico e infindável (SANTOS, 2010).

Cabe identificar o prazer e desprazer, o amor e o ódio diante de uma mesma relação. O trabalho árduo e os estudos são encarados como essa via de mão dupla. A atividade tão bem desenvolvida, com uma demanda alta, bem como exigências e responsabilidades, acaba possibilitando em um grande adoecimento psicológico e fisiológico, possibilitando assim definir o indivíduo workaholic no ambiente de trabalho (SANTOS, 2010).

Existem inúmeras definições sobre o workaholic. Uma delas se distingue em um sujeito envolvido pelo excesso, grande acúmulo de trabalho, o que, muitas vezes, aparentemente apresenta-se um trabalho saudável com satisfação pode assumir um papel ao contrário, gerando um adoecimento e prejuízos em sua rede social e familiar (GOMES; SOARES, 2011).

Diante dessas definições, cabe pontuar o quanto as empresas estão cada vez mais preocupadas com os resultados e não com o que essa carga excessiva de trabalho pode gerar nos funcionários. Funcionários dedicados e que se tornam adoecidos pelo aumento da produtividade, o que gera benefícios para a empresa por gerar cada vez mais lucro para a mesma (STEFANO; STEFANICZEN, 2013).

Para atingir o esperado das empresas, o funcionário tende a escolher momentos entre a vida pessoal e o trabalho, não conseguindo desenvolver um equilíbrio entre ambos, pois deixa de lado sua família e as relações que o acerca pelo compromisso que tem com o mundo laboral, dedicando sempre ao trabalho características estas que demonstram um sujeito adoecido. Como supracitado, as medidas exacerbadas e cobradas pelo trabalho e o excesso dele tanto em realizar atividades dentro da empresa como também os trabalhos que realiza no ambiente familiar, acabam resultando no adoecimento (SANTOS 2010). 
Diante desse contexto, temos diversos atores: de um lado, empresas que buscam o máximo de desempenho de seus funcionários e do outro, funcionários que tentam cumprir aquilo pelo que são cobrados, tentando, muitas vezes, atingir o inatingível e se esgotando por tal (SANTOS, 2010).

Para compreender a relação estrutural, este artigo irá utilizar e destacar duas escolas importantes que discutem sobre o adoecimento no mundo do trabalho, sendo a primeira a psicodinâmica no trabalho e a segunda a escola comportamental do estresse, fundamentos esses úteis que estudam e intervém quando o assunto é o adoecimento psicológico, físico e social do sujeito.

\subsection{ESCOLA COMPORTAMENTAL DO ESTRESSE.}

Com a correria do dia a dia, o desemprego, os desafios, as preocupações, a falta do lazer, o distanciamento da família, dentre outros fatores concomitantes, promove o surgimento do fator de estresse e consequentemente acometendo o adoecimento (STEFANO; STEFANICZEN, 2013).

Podemos definir o fator estresse como:

uma reação do organismo, com componentes físicos e/ou psicológicos, causada pelas alterações psicofisiológicas que ocorrem quando a pessoa se confronta com uma situação que, de um modo ou de outro, a irrite, amedronte, excite ou confunda, ou mesmo que a faça imensamente feliz (LIPP; MALAGRIS, 2001, p.477).

Portanto, compreende-se que o estresse é o fator causal de alterações de comportamentos do sujeito mediante os antecedentes diferentes que o sujeito está habituado a conviver. A manutenção desses fatores em longo prazo ocasiona assim estresse instaurado. Perante os desafios diários a que é submetido (sendo frustrações, preocupações, a falta de lazer e o excesso de trabalho), o sujeito acaba sendo afetado e potencializa o fator estressor, consequentemente amplia a tendência de afetar diretamente outros âmbitos da vida de tal, sendo pensado na vida emocional, física e social. Compreende-se, portanto, que fatores internos e externos de sua 
vivência desencadeiam no adoecimento mediante a todo esse processo (ELIAS, 2013).

O workaholic, e suas características como a compulsão e o vício pelo trabalho, quando associado a níveis altos de estresse, possibilitam, portanto, o adoecimento, afetando sua saúde de forma integral. Esses sujeitos têm como características serem compulsivos, motivados, perfeccionista, intensificando as relações com os colegas de trabalho afetados diretamente por essas características, propiciando assim desconfiança na equipe de trabalho (GOMES, 2016).

O cientista canadense Hans Selye, nas décadas de 1960, 1970, estudou o estresse biológico e Sadir, Bignotto e Lipp (2010, p.73) embasados no cientista, definiram-no como "uma reação do organismo que ocorre frente a situações que exijam dele adaptações além do seu limite", sendo possível pensar que para causar o adoecimento no sujeito, deve haver uma ultrapassagem entre o que o sujeito suporta para um campo desconhecido e fora de seu limite, atingindo o corpo e a mente do sujeito, impossibilitando que haja qualidade de vida laboral, expandindo para a falta de qualidade de vida social (SADIR; BIGNOTTO; LIPP, 2010).

No mundo do trabalho, com exigências, prazos, demandas envolve-se uma implicação total do sujeito workaholic imerso nesse plano trazendo serias consequências. O estresse, esgotamento físico e mental, dores físicas em diversas regiões do corpo é notável ao acumulo de trabalho, bem como o afastamento das relações familiares e sociais (SERVA; FERREIRA, 2006).

Neste contexto laboral há uma demanda de possíveis agentes estressores ao sujeito, como uma administração desorganizada, a falta de conhecimento de ambos os cargos bem como a ausência de cursos, acidentes de trabalho, carga horária desigual, salário, ambiente, competitividade, mudanças, lideranças, comunicação dentre outros agentes e fatores aos quais existem dentro da empresa e que causam uma frequência de adoecimento ao sujeito, prejudicando o mesmo em todos os âmbitos de sua vida, seja profissional ou pessoal (REIS; FERNANDES, 2010). 
Por conseguinte esses agentes estressores podem estar presentes ao sujeito workaholic, o que irá diferenciar é a intencionalidade aos fatores estressores comportamentais que cada indivíduo vai ter diante da resposta, estimulo da demanda exposta, seja ela por um conflito, esquiva ou aversão a quaisquer fatores proveniente de estresse. É importante salientar que toda mudança ou conflito gera uma consequência de resposta do comportamento e uma percepção diferente, possibilitando assim em um adoecimento (REIS; FERNANDES, 2010).

\subsection{PSICODINÂMICA DO TRABALHO}

A outra escola que abordaremos nesse artigo, é a psicodinâmica do trabalho. Mostrando sua atuação com as especificidades e intervenções, perante uma sociedade e os moldes exigentes que parte de uma visão posta ao coletivo e ao individual particular, ambas provém de um adoecimento. Mendes (2007) suscita que:

é objeto da psicodinâmica do trabalho o estudo das relações dinâmicas entre organização do trabalho e processos de subjetivação, que se manifestam nas vivências de prazer-sofrimento, nas estratégias de ação para mediar contradições da organização do trabalho, nas patologias sociais, na saúde e no adoecimento (MENDES, 2007, p. 30).

Nesse meandro, cabe ressaltar que as organizações não se atentam as particularidades, as relações, às frustrações, desafios e os problemas passam a não ser vistos e o adoecimento é inevitável perante todo esse processo de trabalho (MERLO; MENDES, 2009).

Logo o que importa é o coletivo, a quantidade e o excesso de trabalho, não havendo sequer uma preocupação com possíveis medidas de intervenção ao sofrimento. Diante de pressões de trabalho e o sofrimento, seria importante a construção de intervenções pautadas ao adoecimento do coletivo através da organização do trabalho dentro das organizações (MERLO; MENDES, 2009).

A psicodinâmica do trabalho deve sempre ter a preocupação de se adequarem ao ambiente de trabalho, estando assim em constante transformação (MERLO; MENDES, 2009). Nesse mesmo sentido, os autores ainda afirmam que: 
[...] com a psicodinâmica do trabalho não ocorre diferentemente. As várias experiências realizadas até hoje por pesquisadores brasileiros utilizando esse método, indicam que o método permite, não apenas produzir uma investigação e, portanto, novos conhecimentos, mas, também, revela-se um instrumento para intervenção, prevenção e transformação de processos de trabalho agressivos à saúde psíquica (MERLO; MENDES, 2009, p.12).

Dentro desse contexto, Giongo; Monteiro e Sobrosa (2015) mencionam que a psicodinâmica exerce um papel fundamental quando se fala em processos de saúde/doença do trabalhador, pois ela acontece na relação entre as vivências do trabalhador relacionadas à organização do trabalho. Deste modo:

saúde no trabalho não significa ausência de sofrimento, mas o potencial que cada trabalhador possui de utilização dos recursos internos e externos para transformação do sofrimento na busca pelo prazer e realização" (GIONGO; MONTEIRO; SOBROSA, p. 805, 2015).

Debaixo desse meandro, pode-se pensar que o trabalhador workaholic vivencia prazer e sofrimento a todo o momento, sendo que a relação explicita o potencial que cada sujeito tem de utilizar-se de seus recursos internos e externos para lidar com as situações. De acordo com os autores, há possibilidades "de mobilizar os trabalhadores de maneira individual ou coletiva, estabelecendo uma relação mais gratificante com o trabalho" (GIONGO; MONTEIRO; SOBROSA, 2015. p. 805).

Outro ponto necessário pertencente à Psicodinâmica do Trabalho é a relação entre o trabalho prescrito e trabalho real, havendo entre os dois um distanciamento na execução das atividades referente ao que o trabalho prescrito preconiza e a forma que o trabalho real se efetiva. Dejours (2004) salienta que o campo do trabalho prescrito não acontece como deveria, fazendo com que o trabalhador desenvolva seu ritmo pautando-se em um trabalho diferente do acordado, e esse "fazer" diferentemente do acordo, para o autor, é nomeado de trabalho real, muitas vezes, o causador do afastamento da realização do trabalhador, acarretando o adoecimento físico e mental, chegando ao esgotamento.

O trabalho prescrito abrange as funções que são atribuídas ao cargo pelo qual o sujeito foi contratado, sendo para o sujeito workaholic algo não palpável visto que sua 
interação com o trabalho sempre será intencionada a realizar além de suas atividades. Entretanto, o trabalho real pode ser compreendido como as funções que o trabalhador realiza diariamente, as ações diárias, não necessariamente atribuídas à função pelo qual foi contratado e para o sujeito workaholic esse trabalho real torna-se um dos fatores de adoecimento, visto que para fazer-se cumprir aquilo que the é solicitado, o workaholic tende a realizar suas jornadas de trabalho em excesso, também não dimensionando sobre realizar as atividades laborais fora de seu ambiente de trabalho, demonstrando não conseguir separar esse ambiente dos demais (GIONGO; MONTEIRO e SOBROSA, 2015).

\section{ANÁLISE}

Após discorrer sobre o sujeito workaholic imerso no mundo do trabalho, bem como suas implicações, influências sociais e profissionais diante desse cenário, cabe a esta pesquisa ressaltar que os profissionais da Psicologia podem contribuir com os cuidados de prevenção primária, bem como, cuidados posteriores diante do sujeito adoecido.

Como citado ao decorrer desta pesquisa, esse adoecimento se desenvolve devido às questões relativas a pressões da rotina laboral, descompensando as demais relações sociais. Mendes menciona que:

Desvelar a o sofrimento pela fala permite resgatar a capacidade de pensar sobre o trabalho, é um modo de desalienação, bem como uma possibilidade de apropriação e dominação do trabalho pelos trabalhadores (2007, p.32).

A explanação da autora possibilita a inclinação à prática do psicólogo do trabalho, que mediante ao contexto das organizações necessita ampliar o espaço de fala de seus colaboradores, propiciando que a haja mobilização e engajamento por parte da organização do trabalho sobre o que está sendo exigido de seu trabalhador.

Segundo Guirado "o papel do psicólogo defini-se como o de mobilizar a construção e apropriação por parte do sujeito de um conhecimento sobre si nas relações que vivencia" (2004, p.71), ou seja, pode ser compreendido como um possibilitador de 
promover o outro olhar para si, dando respaldo às funções psíquicas que serão utilizadas

Quando referido a função do profissional dentro das organizações, os autores mencionam que:

Em suma, o papel do psicólogo dentro das organizações é atuar como facilitador e conscientizador do papel dos vários grupos que compõem a instituição, considerando a saúde e a subjetividade dos indivíduos, a dinâmica da empresa e a sua inserção no contexto mais amplo da organização (CAMPOS et al., 2011, p.705)

Corroborando com a explanação referente ao papel do psicólogo do trabalho, Guirado (2004) complementa que a atuação deve ser relevante para o desenvolvimento do sujeito ou grupo, sendo realizada de modo responsável a maneira como o profissional irá conduzir e intervir diante dos acontecimentos e conflitos existentes.

Por conseguinte, vale ressaltar a importância do papel do Psicólogo dentro das organizações, visto que ele deve buscar por diversas estratégias e ferramentas que irão auxiliar o sujeito nesse campo, com treinamentos e técnicas, podendo desenvolver "implantar programas de saúde, proteção, valorização e satisfação do trabalhador, garantindo o acesso a bens e serviços" (BORGES; OLIVEIRA; MORAIS, 2005, p.110), entretanto,

muitos trabalhadores acreditam que apenas passando pelo psicólogo da organização já é o suficiente, mas só cabe ao psicólogo organizacional reconhecer distúrbios comportamentais dos trabalhadores e fazer a indicação correta psicoterápica (SOARES, 2018, p.2)

Sendo assim, compreende-se que quando há demandas que ultrapassam os limites de cuidado dentro da organização, cabe ao psicólogo identificar e encaminhar esse sujeito para uma possível intervenção individual (SILVA, 2015).

Como base para prática do profissional da Psicologia é necessário nos remeter sempre a ética da categoria, buscando ferramentas e estratégicas, bem como a busca por intervenções pertinentes (DIAS; SOARES, 2007). Portanto, é responsabilidade 
desse profissional observar as relações laborais, para através de intervenções possibilitar um ambiente em que os sujeitos se sintam partes pertencentes ao grupo.

Ao retomar como a escola comportamental do estresse identifica os fatores no ambiente laboral que propiciam o estresse físico e emocional, pode-se dizer que o ambiente laboral possui fatores que condicionam o adoecimento do sujeito, portanto o profissional da psicologia do trabalho e as organizações devem compreender que cada indivíduo é um ser singular, tendo suas diferenças e desenvolve repertórios próprios para lidar com os conflitos. (REIS; FERNANDES, 2010).

Destaca-se nesse momento que na atividade profissional, a base e ferramenta que deve ser utilizada em qualquer área de atuação é o Código de Ética da Psicologia, sendo que ele traz orientações sobre a prática profissional, fazendo alusão que esta deve ser direcionada aos sujeitos, laços sociais bem como dimensões culturais (Código de Ética, 2005), ou seja, Código de Ética desse profissional afirma a necessidade de observações, cuidados ao atuar para que não haja uma prática profissional elitista ou segregadora. Como supracitado segundo o Código de ética, (2005, p.05).

A missão primordial de um código de ética profissional não é de normatizar a natureza técnica do trabalho, e, sim, a de assegurar dentro de valores relevantes para a sociedade e para as práticas desenvolvidas, um padrão de conduta que fortaleça o reconhecimento social daquela categoria. (CÓDIGO DE ÉTICA, 2005, p.05).

Retomando a necessidade do profissional da psicologia na busca por desenvolver seu trabalho, tendo como fundamento base o Código de Ética (2005) profissional, para realizar de forma coerente e diretiva, o referido deve sempre buscar por estratégias que possibilitem auxiliar o sujeito em meio ao adoecimento.

Neste momento, vale apontar que além de desenvolver o trabalho como profissional da psicologia dentro das organizações, quando é compreendido que o sujeito adoecido necessita de demais cuidados, cabe a esse profissional encaminhar para a psicoterapia, visto que o tema trabalhado no ambiente da organização trata-se de questões relacionadas apenas ao âmbito laboral. 
Existem parcerias entre setores públicos e privados, que acabam sendo outras ferramentas para contribuir, incentivar e ajudar o sujeito. Devido à importância e a necessidade de desenvolver projetos capacitados para auxiliar o sujeito adoecido. Estratégias essas que trazem consequências e benefícios, pois ás parcerias nesses setores acaba ajudando com as prestações de serviço e atendimentos médicos (THAMER; LAZZARINI, 2015).

Para que essa prática ocorra de forma coerente, o profissional precisa desmistificar desde o processo da graduação, práticas em prol do individualismo, de crenças impostas ao social, quebrando tabus sobre a sociedade e quando mencionar o profissional para atuar no campo organizacional, ele necessita compreender todo o processo histórico de como foi sendo transformada e chegando até os meandros atuais a organização do trabalho, para conseguir efetivar uma atuação coerente e em prol da sociedade como um todo.

\section{CONSIDERAÇÕES FINAIS}

De acordo com os objetivos e com a problemática apresentada neste trabalho foi possível identificar, compreender e contextualizar o adoecimento do sujeito workaholic em detrimento de sua rotina laboral e os fatores físicos, psicológicos e sociais decorrente do adoecimento, principalmente o quanto esse sujeito sofre consequências de não vivenciar relações saudáveis em sua vida social.

Assim, a pesquisa aqui desenvolvida trouxe dados que ressaltam a importância do psicólogo dentro das organizações, quando qualificado para a atuação, visto que o profissional da Psicologia pode auxiliar com os conteúdos voltados a sua formação dentro e fora da organização (SANTOS et al., 2010).

Mediante a necessidade de contextualizar as mudanças, influencias e as relações do adoecimento no sujeito workaholic, o psicólogo identificando esses fatores tem funcionalidade para auxiliar no processo para com os cuidados preventivos ao sujeito workaholic, visto que o homem analisado se transforma por meio do ambiente, das 
relações que o cerca, do trabalho a ser desenvolvido de toda a contextualização (VIEIRA; BARROS; LIMA. 2007).

Pode se destacar também a existência de algumas estratégias com intuito de auxiliar o profissional na busca por medidas e intervenções ao adoecimento no processo do trabalho. Entretanto, necessita tomar ciência que nenhum método é eficaz sozinho. Temos muitos limitadores e dificuldades e assim precisamos ter cautela para passível ação eficaz (MERLO; MENDES, 2009).

Conclui-se o quanto o trabalho pode vir a enfraquecer ou fortalecer a compreensão do sujeito sobre si, através da análise das relações de prazer e desprazer do sujeito no contexto laboral e suas consequências para o contexto social, o Psicólogo deve ser funcional ao mostrar caminhos que auxiliem na buscar pelo equilíbrio entre o contexto laboral e social do sujeito, proporcionando a quebra de paradigmas sobre o trabalhador, visto que esse é apenas um dos papéis que o sujeito representa na sociedade.

Devido ao adoecimento em larga escala dentro das organizações, justifica a necessidade futura da produção cientifica voltada ao tema abordado nesta pesquisa e estudos relevantes que propiciem a visibilidade do sujeito workaholic, corroborando para olhares relativos ao cuidado de tal, sendo o profissional da Psicologia capacitado para auxiliar na prevenção e cuidados na busca pelo equilíbrio do sujeito, assim está pesquisa deixa a porta aberta para futuros pesquisadores da área.

\section{REFERÊNCIAS}

BORGES, Livia de Oliveira; OLIVEIRA, Andréa Carla Ferreira de; MORAIS, La Thude Wolvua Almeida de. O exercício do papel profissional na Psicologia Organizacional e do Trabalho. Rev. Psicol., Organ. Trab., Florianópolis , v. 5, n. 2, p. 101-139, dez. 2005

Disponível

em:

$<$ http://pepsic.bvsalud.org/scielo.php?script=sci_arttext\&pid=S1984-

66572005000200005\&lng=pt\&nrm=iso >. Acesso em 30 Abr. 2020. 
CAMPOS, Keli Cristina de Lara et al. Psicologia organizacional e do trabalho - retrato da produção científica na última década. Psicol. cienc. prof., Brasília , v. 31, n. 4, p. 702-717, 2011

Disponível em: $<$ http://www.scielo.br/scielo.php?script=sci_arttext\&pid=S141498932011000400004\&lng=en\&nrm=iso>. Acesso em: 30 Abr. 2020.

COELHO, Maria Thereza Ávila Dantas; ALMEIDA FILHO, Naomar de. Análise do conceito de saúde a partir da epistemologia de Canguilhem e Foucault. In: GOLDENBERG, P; GMARSIGLIA, RM; GOMES, MHA. Cultura e subjetividade: os sentidos da saúde. Rio de Janeiro: Fiocruz, 2003.

CÓDIGO DE ÉTICA PROFISSIONAL DO PSICÓLOGO, 2005. Conselho regional de Psicologia.

em: <http://www.crpsp.org.br/portal/orientacao/codigo/fr_codigo_etica_new.aspx> acesso em 22 mar. 2020

DEJOURS, Christophe. Subjetividade, trabalho e ação. Revista Produção, v. 14, n. 3, p. 027-034, Set./Dez. 2004.

DIAS, Maria Sara de Lima; SOARES, Dulce Helena Penna. Jovem, Mostre a Sua Cara: Um estudo das possibilidades e limites da escolha profissional. Psicologia Ciências e Profissão, p.316-331, 27 fev. 2007.

ELIAS, Adrieli da Silveira. Estresse Gerando A Síndrome De Burnout. 42 f. Tese (Doutorado) - Curso de Administração, Universidade do Extremo Sul Catarinense Unesc Curso de Especialização em Saúde Mental, Criciuma, 2013. Disponível em: http://repositorio.unesc.net/bitstream/1/1780/1/Adrieli\%20da\%20Silveira\%20Elias.pdf . Acesso em: 17 mar. 2020.

GERHARDT, Tatiana Engel; SILVEIRA, Denise Tolfo (Orgs). Métodos de pesquisa. Porto Alegre: Editora UFRGS, 2009.

GIONGO, Carmem Regina; MONTEIRO, Janine Kieling; SOBROSA, Gênesis Marimar Rodrigues. Psicodinâmica do trabalho no Brasil: revisão sistemática da literatura. 
Temas psicol., Ribeirão Preto, v. 23, n. 4, p. 803-814, dez. 2015 . Disponível em: $<$ http://pepsic.bvsalud.org/scielo.php?script=sci_arttext\&pid=S1413389X2015000400002\&Ing=pt\&nrm=iso $>$. Acessos em: 22 mar. 2020.

GOMES, Jorge F. S.; SOARES, Patrícia. O excesso de trabalho mata ou dá prazer? Uma exploração dos antecedentes e consequentes do workaholismo. Psicologia, Lisboa, v. 25, n. 1, p. 51-72, jun. 2011 . Disponível em:<http://www.scielo.mec.pt/scielo.php?script=sci_arttext\&pid=S087420492011000100003\&lng=pt\&nrm=iso>. Acesso em: 05 mar. 2020.

GOMES, Tailá Santiago. Workaholism, alienação e fatores de risco laborais e psicossociais: Uma revisão sistemática na literatura brasileira. 2016. $24 \mathrm{f}$. Trabalho de Conclusão de Curso (Graduação em Psicologia) - Universidade Estadual da Paraíba, Campina Grande, $2016 . \quad$ Disponível em: $\quad$ <http://dspace.bc.uepb.edu.br/jspui/bitstream/123456789/11965/1/PDF\%20\%20Tha\%c3\%adla\%20Santiago\%20Gomes.pdf>_Acesso em: 29 Fev. 2020

GUIRADO Marlene. Instituição e Relações Afetivas: 0 vínculo com o abandono. São Paulo: Casa dos Psicólogos; 2004.

GUIRADO, Marlene. Psicologia Institucional: em busca da especificidade de atuação do psicólogo. Psicologia Institucional, cap4. P.65-85. 2004.

LAKATOS, E. M.; MARCONI, M. de A. Fundamentos de metodologia científica. São Paulo: Atlas, 2003. p.310 Disponível em: <https://docente.ifrn.edu.br/olivianeta/ disciplinas/copy_of_historia-i/historia-ii/china-e-india> Acesso em : 22 de Abril de 2020.

LIPP, M. E. N., \& Malagris, L. E. N. O stress emocional e seu tratamento. In B. Rangé (Org). Psicoterapias cognitivo-comportamentais: um diálogo com a psiquiatria (pp.475-490). Porto Alegre: Artmed. (2001).

MENDES, Ana Magnólia. Psicodinâmica do trabalho: teoria método e pesquisas. São Paulo: Casa do Psicólogo; 2007. 
MERLO, Álvaro Roberto Crespo; MENDES, Ana Magnólia Bezerra. Perspectivas do uso da psicodinâmica do trabalho no Brasil: teoria, pesquisa e ação. Cad. psicol. soc. trab., São Paulo, v.12, n.2, p.141-156, dez. 2009. Disponível em: <http://pepsic.bvsalud.org/scielo.php?script=sci_arttext\&pid=S1516$37172009000200002 \&$ lng=pt\&nrm=iso> Acesso em: 18 mar. 2020.

REIS, Ana Lúcia Pellegrini Pessoa dos; FERNANDES, Sônia Regina Pereira; GOMES, Almiralva Ferraz. Estresse e fatores psicossociais. Psicol. cienc. prof., Brasília , v. 30, n. 4, p. 712-725, Dez. 2010 . Disponível em: $<\mathrm{http}: / / w w w . s c i e l o . b r / s c i e l o . p h p ? s c r i p t=s c i \_a r t t e x t \& p i d=S 1414-$ 98932010000400004\&lng=en\&nrm=iso>. Acesso em: 21 Abr. 2020.

SADIR, Maria Angélica; BIGNOTTO, Márcia Maria; LIPP, Marilda Emmanuel Novaes. Stress e qualidade de vida: influência de algumas variáveis pessoais. Paidéia (Ribeirão Preto), Ribeirão Preto, v. 20, n. 45, p. 73-81, Abr. 2010. Disponível em: $<$ <ttp://www.scielo.br/scielo.php?script=sci_arttext\&pid=S0103863X2010000100010\&Ing=en\&nrm=iso >. Acesso em: 21 Mar. 2020

SANTOS, Ludmilla Cristine et al . Psicologia e profissão: neurose profissional e a atuação do psicólogo organizacional frente à questão. Psicol. cienc. prof., Brasília v. 30, n. 2, p. 248-261, 2010 . Disponível em: $<\mathrm{http}: / /$ www.scielo.br/scielo.php?script=sci_arttext\&pid=S141498932010000200003\&Ing=en\&nrm=iso>. Acesso em: 16 Mar. 2020.

SANTOS, Patrícia Almeida dos. Workaholic: Uma Relaçao De Prazer Ou Sofrimento? 2010. 164 f. TCC, Pedro Leopoldo, Belo Horizonte, 2010. Disponível em: https://www.fpl.edu.br/2018/media/pdfs/mestrado/dissertacoes_2010/dissertacao_pat ricia_almeida_dos_santos_2010.pdf. Acesso em: 16 mar. 2020.

SERVA, Maurício; FERREIRA, Joel Lincoln Oliveira. O fenômeno workaholic na gestão de empresas. Rev. Adm. Pública, Rio de Janeiro, v. 40, n. 2, p. 179198, Abr. 2006.

Disponível

em: 
$<$ http://www.scielo.br/scielo.php?script=sci_arttext\&pid=S0034-

76122006000200002\&lng=en\&nrm=iso>. Acesso em: 29 Fev. 2020.

SILVA, Débora de Paula da; SILVA, Maria de Nazareth Rodrigues Malcher de Oliveira. O TRABALHADOR COM ESTRESSE E INTERVENÇÕES PARA O CUIDADO EM SAÚDE. Trab. educ. saúde, Rio de Janeiro , v. 13, supl. 1, p. 201-214, 2015

Acesso em: <http://www.scielo.br/scielo.php?script=sci_arttext\&pid=S198177462015000400201\&lng=en\&nrm=iso>. Disponível em: 26 Abr. 2020.

SOARES, Aline Raquel de Lima. A influência do workaholismo no comportamento interpessoal em empresas. 2018. Disponível em: https://www.psicologia.pt/artigos/textos/A1163.pdf Acesso em: 29 Fev. 2020.

SOUZA, Heloisa Aparecida; BERNARDO, Marcia Hespanhol. Prevenção de adoecimento mental relacionado ao trabalho: a práxis de profissionais do Sistema Único de Saúde comprometidos com a saúde do trabalhador. Rev. bras. saúde ocup., São Paulo , v. 44, e26, 2019 . Disponível em: $<$ http://www.scielo.br/scielo.php?script=sci_arttext\&pid=S030376572019000100302\&Ing=en\&nrm=iso>. Acesso em: 03 Mar. 2020.

STEFANO, Silvio Roberto; STEFANICZEN, Josemara. Workaholic: Um Novo Modelo De Comportamento Nas Organizações. Revista Ciências Sociais em Vol. 12 - № 23 - $2^{\circ} \quad$ Semestre, 2013.2 Disponível em: http://www.sgc.goias.gov.br/upload/arquivos/2013-04/area-tematica--gestao-depessoas-workaholic-um-novo-modelo-de-comportamento-nas-organizacoes.pdf. Acesso em: 16 mar. 2020.

THAMER, Rogério; LAZZARINI, Sérgio Giovanetti. Projetos de parceria públicoprivada: fatores que influenciam o avanço dessas iniciativas. Rev. Adm. Pública, Rio de Janeiro , v. 49, n.4, p.819-846, Aug. 2015. Disponível em: $<$ http://www.scielo.br/scielo.php?script=sci_arttext\&pid=S003476122015000400819\& Ing=en\&nrm=iso>. Acesso em: 26 Abr. 2020. 
VIEIRA, Carlos Eduardo Carrusca; BARROS, Vanessa Andrade; LIMA, Francisco de Paula Antunes. Uma abordagem da psicologia do trabalho, na presença do trabalho. Psicol. rev. (Belo Horizonte), Belo Horizonte, v.13, n. 1, p. 155168, jun. 2007. Disponível em:

<http://pepsic.bvsalud.org/scielo.php?script=sci_arttext\&pid=S1677-

11682007000100010\&lng=pt\&nrm=iso >. Acesso em: 04 Mar. 2020.

Enviado: Junho, 2020.

Aprovado: Novembro, 2020. 